\title{
Halloween Candy Transporter
}

\author{
Jennifer Hull ${ }^{1}$
}

${ }^{1}$ Affiliation not available

May 3, 2021

\section{Suggested Time:}

55 minutes

\section{Grade Level:}

Kindergarten, First Grade, Second Grade

\section{Overview:}

One of the most anticipated days in the life of a child is Halloween! Kids wait all year for the one night to fill their bags with candy. Due to the COVID-19 pandemic and social distancing guidelines, some communities cancelled Halloween. Students will brainstorm ways for adults to pass out candy so kids can go trick-or-treating while still maintaining a social distance of six feet.

\section{NGSS Standards:}

- K-2-ETS1-1 Ask questions, make observations, and gather information about a situation people want to change, to define a simple problem that can be solved through the development of a new or improved object or tool.

- K-2-ETS1-2 Develop a simple sketch, drawing, or physical model to illustrate how the shape of an object helps it function as needed to solve a given problem.

- K-2-ETS1-3 Analyze data from tests of two objects designed to solve the same problem to compare the strengths and weaknesses of how each performs.

\section{Objectives:}

\section{Students will use the engineering design process to:}

Brainstorm ways to deliver a piece of candy a distance of 6 feet

Sketch a drawing of their plan

Use materials to create a prototype 
Perform a test

Record data

Share their solution with the class

\section{Vocabulary:}

ramp, incline, push, pull, pulley, simple machine, measure, angle, build, design, test

\section{Suggested Materials:}

- paper towel tubes

- tape

- string

- spools

- Legos

- wheels

- popsicle sticks

- straws

- pipe cleaners

- cardboard

- small toy cars

- small pieces of Halloween candy

\section{The Lesson:}

1. Students will gather in groups of 3-4 and use creativity to brainstorm ideas. They will make a simple sketch of their plan. (See Halloween Transporter Design.docx)

2. Students will gather their materials.

3. Students will collaborate to construct their device. (There are many possible solutions. Possible ideas: use something to push the candy 6 feet to a trick-or-treater, build a chute or ramp to send the candy, use a pulley system with string)

4. Students will perform tests to see if their device works correctly. Measure how far the candy went. Problem solve ways to make improvements. Does the angle of the device make a difference?

5. Students will record their results. (See Halloween Transporter Results.docx)

6. Students will share their project with the class.

7. The class will determine which projects would be the most useful.

\section{Hosted file}

Halloween Transporter Results.docx available at https://authorea.com/users/408209/articles/ 519770-halloween-candy-transporter

\section{Hosted file}

Halloween Transporter Design.docx available at https://authorea.com/users/408209/articles/ 519770-halloween-candy-transporter 


\section{Extension:}

This activity could be adapted for use with upper grades. The use of technology could also be incorporated. Students could incorporate the use of a catapult or code a robot to deliver the candy. Students could also create a switch or timer to deliver candy automatically. 